\title{
Bimbingan Teknik Budidaya Tumbuhan Obat Untuk Penyediaan Simplisia Obat Herbal Bagi Masyarakat
}

\author{
Rosmini*1, Sri Anjar Lasmini $^{2}$, Andi Ete ${ }^{3}$, Dwi Rohma Wulandari ${ }^{4}$, Nur Edy5 ${ }^{5}$ Nur Hayati6 ${ }^{6}$ Asgar \\ Taeyeb $^{7}$ \\ 1,2,3,5,6,Program Studi Agroteknologi Fakultas Pertanian Universitas Tadulako \\ ${ }^{4}$ Program Studi Komunikasi Fakultas Ilmu Sosial dan Ilmu Politik Universitas Tadulako \\ ${ }^{7}$ Program Studi Kehutanan Fakultas Kehutanan Universitas Tadulako \\ *e-mail: rhosmini.rosmini@gmail.com
}

\begin{abstract}
The cultivation of rare and or wild medicinal plants is one of the strategies to make it easier when needed and also to produce quality simplicia. The partner village program aims to assist the community in carrying out medicinal plant cultivation. The community service activities were carried out in the conservation area of medicinal plants and in the residents' yards in Pakuli Village and lasted for 4 months, from March 2020 to July 2020. The method applied was counseling and technical guidance. The results of the activities showed that the training and technology demonstration were well implemented and were accepted by the community. Counseling activities increase knowledge that is characterized by increased skills when practicing medicinal plants. Species that are cultivated in conservation areas are those that grow wild and rare, while in people's yards it is the species most widely used as medicine and which is of economic value.
\end{abstract}

Keywords: family medicinal plants, living pharmacies, natural ingredients

\section{Abstrak}

Budidaya tumbuhan obat yang langka dan atau tumbuh liar merupakan salah satu strategi untuk memudahkan saat diperlukan untuk pengobatan dan juga untuk menghasilkan simplisia yang berkualitas. Program desa mitra bertujuan untuk mendampingi masyarakat melaksanakan budidaya tumbuhan obat. Kegiatan pengabdian ini dilaksanakan di area konservasi tumbuhan obat dan di lahan pekarangan masyarakat di Desa Pakuli Kecamatan Gumbasa dan berlangsung selama 4 bulan yakni bulan Maret 2020 sampai dengan Juli 2020. Metode yang diterapkan adalah penyuluhan dan bimbingan teknik. Hasil kegiatan menunjukkan bahwa pelatihan dan demonstrasi teknologi terlaksana dengan baik dan diterima oleh masyarakat. Pelaksanaan penyuluhan meningkatkan pengetahuan masyarakat yang ditandai dengan meningkatnya ketrampilan pada saat praktek budidaya tumbuhan obat. Jenis tumbuhan obat yang dibudidayakan di area konservasi adalah yang tergolong tumbuh liar dan langka, sedangkan di lahan pekarangan adalah jenis yang paling banyak dimanfaatkan sebagai obat dan yang bernilai ekonomi.

Kata kunci: apotik hidup, bahan alam, tanaman obat keluarga

\section{PENDAHULUAN}

Tren gaya hidup yang kembali ke alam (back to nature) mengakibatkan masyarakat kembali memanfaatkan bahan alam, termasuk pengobatan dengan menggunakan tanaman berkhasiat obat. Salah satu faktor penyebab penggunaan tanaman berkhasiat obat tersebut adalah relatif lebih aman dan tidak menimbulkan efek samping seperti yang sering ditimbulkan oleh obat-obatan kimia (Tampubolon, 1981). Tanaman berkhasiat obat adalah tumbuhan yang bagian tertentu atau seluruh bagian dari tumbuhan diyakini atau dipercaya dapat dimanfaatkan sebagai penghilang rasa sakit atau sebagai salah satu obat penyembuh dari suatu penyakit (Suriawiria, 2000). Bagian tumbuhan yang dimaksud adalah daun, buah, bunga, akar, rimpang, batang (kulit) dan getah (resin).

Tumbuhan obat (TO) umumnya diperoleh dari halaman rumah yang sengaja ditanam atau di kebun, di pinggiran sawah, bahkan di areal hutan yang tumbuh liar dan tidak dibudidayakan, sehingga apabila diperlukan masyarakat, membutuhkan waktu untuk mencari TO tersebut. Untuk memudahkan masyarakat dalam memanfaatkan TO terutama yang tergolong liar dan langka, maka perlu dilestarikan agar mudah diperoleh dan tidak mengalami kelangkaan (Parwata, 2016). 
Upaya pelestarian TO terutama yang tumbuh liar dan yang tergolong langka dapat ditempuh dengan melakukan konservasi TO, baik secara in-situ maupun dengan ex-situ. Konservasi in-situ dilakukan dengan cara mengelola secara baik kawasan-kawasan hutan yang merupakan habitat asli sehingga memberikan perlindungan terhadap TO yang ada di dalamnya. Konservasi ex-situ merupakan kegiatan perlindungan yang dilakukan diluar habitat asli. Konservasi ex-situ juga dapat disebut sebagai tindakan domestikasi tumbuhan sehingga pada akhirnya dapat dibudidayakan secara luas (Leakey \& Newton, 1994 ).

Tanaman obat akan lebih berkhasiat jika digunakan dalam keadaan segar. Hal tersebut dapat disiasati dengan menanam tanaman obat dalam sekala kecil di pekarangan rumah. Dengan demikian, selain sebagai tanaman obat keluarga (TOGA) juga dapat dijadikan usaha sampingan bagi para ibu rumah tangga (Ashari $d k k$., 2012). Lahan pekarangan yang ditanami TO secara tradisional dikenal sebagai apotik hidup (Nurmayulis \& Hermita, 2015; Sari dkk., 2015).

Dalam dunia farmasi, bahan mentah untuk obat-obatan disebut dengan simplisia yaitu bahan alami yang dipergunakan sebagai obat yang belum mengalami pengolahan apapun dan berupa bahan yang telah dikeringkan (Departemen Kesehatan RI, 1983). Simplisia terdiri dari 3 macam yaitu simplisia nabati adalah simplisia yang berupa tanaman utuh, bagian tanaman atau eksudat tanaman dan belum berupa zat kimia murni, simplisia hewani adalah simplisia yang merupakan hewan utuh, sebagian hewan atau zat-zat berguna yang dihasilkan oleh hewan dan belum berupa zat kimia murni, dan simplisia pelikan atau mineral adalah simplisia yang berupa bahan pelikan atau mineral yang belum diolah dengan cara yang sederhana dan belum berupa zat kimia murni.

Budidaya tanaman didefinisikan sebagai segala usaha manusia yang diterapkan pada suatu kegiatan penanaman tanaman yang diharapkan akan diperoleh hasil yang lebih baik bila dibandingkan tanpa usaha budidaya. Dengan demikian budidaya tanaman obat dimaksudkan untuk menghasilkan simplisia yang berkualitas (Kementerian Kesehatan RI, 2011) dan memudahkan untuk diperoleh bila sewaktu-waktu dibutuhkan sebagai obat bagi keluarga yang sakit (Nasriaty \& Pujiharti, 2012).

Dengan mengkonservasi tumbuhan yang berkhasiat obat terutama yang tergolong liar dan langka melalui budidaya tanaman obat diharapkan ketersediaan bahan baku obat (simplisia) untuk diformulasi menjadi obat tradisional dan atau obat herbal terstandarisasi dapat terjamin kualitasnya. Pogram pengembangan desa mitra ini bertujuan untuk melakukan bimbingan teknik budidaya TO kepada masyarakat agar TO yang tergolong tumbuh liar dan langka dapat dilestarikan dan tidak mengalami kepunahan serta dapat menyediakan simplisia obat herbal yang mudah diperoleh dengan kualitas yang terjamin.

\section{METODE}

Program desa mitra dilaksanakan di areal konservasi TO milik kelompok pembudidaya TO “ASYIFA'A dan di lahan pekarangan masyarakat di Desa Pakuli Kecamatan Gumbasa, berlangsung selama 4 bulan yakni bulan Maret 2020 sampai dengan Juli 2020.

Metode yang diterapkan adalah pendidikan masyarakat berupa penyuluhan dan bimbingan teknik (bimtek) kepada masyarakat terutama anggota kelompok tani 'Mantendo' dan kelompok pembudidaya TO 'Asyifa'a' yang menjadi mitra dalam pelaksanaan program desa mitra.

Kegiatan penyuluhan dilakukan dengan metode ceramah dan dilanjutkan dengan diskusi. Materi penyuluhan terdiri dari pengertian tentang TOGA, pentingnya pemanfaatan lahan pekarangan untuk budidaya TO, jenis-jenis TO yang dapat dibudidayakan di lahan pekarangan, serta penanganan panen dan pasca panen TO. Kegiatan bimtek budidaya TO dilakukan dengan sistem demplot yang dilaksanakan dengan membagi peserta dalam kelompok dengan peran yang berbeda yaitu, kelompok pengisian media tanam ke polybag dan kelompok penanaman TO berdasarkan struktur morfologi TO yang berupa pohon, tiang, pancang, semai dan tumbuhan bawah (Tutjuka $d k k ., 2014$ ) 


\section{HASIL DAN PEMBAHASAN}

\section{Penyuluhan teknik budidaya tumbuhan obat}

Penyuluhan teknik budidaya TO dimaksudkan untuk memberikan gambaran tentang cara budidaya agar diperoleh simplisia obat herbal yang bermutu. Sebagaimana diketahui bahwa simplisia obat herbal yang baik sangat tergantung pada kondisi tanaman obat yang akan dipanen. Dengan pemberian penyuluhan kepada peserta, diharapkan dapat memperoleh pengetahuan bagaimana membudidayakan TO yang benar.

Dipandang dari sisi morfologi TO memiliki karakterisitik yang berbeda sehingga teknik budidaya pun berberbeda satu sama lain. Penyuluhan diikuti sebanyak 30 orang yang merupakan perwakilan dari 2 kelompok mitra yakni kelompok tani Mantendo dan kelompok pembudidaya TO Asyifa'a (Gambar 1a). Pada pelaksanaan penyuluhan dan pelatihan tersebut juga dilakukan penyerahan bantuan bibit TO dan peralatan yang diperlukan selama pelatihan (Gambar 1b).

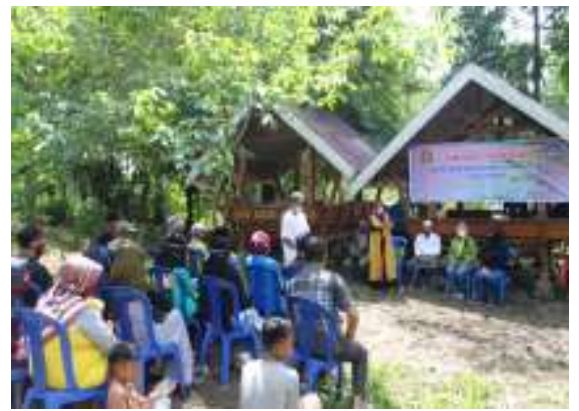

(a)

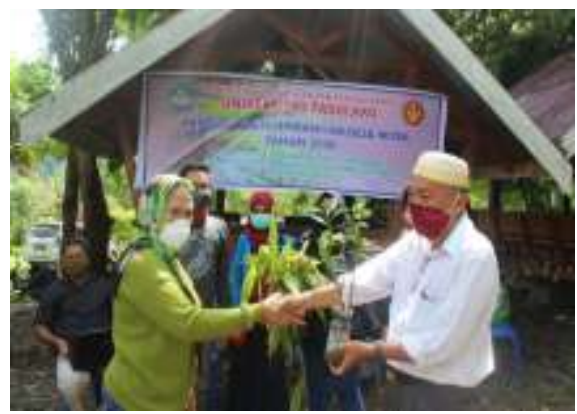

(b)

Gambar 1. (a). Dokumentasi pelaksanaan penyuluhan. (b) penyerahan bibit TO secara simbolis kepada ketua kelompok pembudidaya TO

\section{Pelatihan teknik budidaya tumbuhan obat}

Pelatihan teknik budidaya dilaksanakan di 2 tempat yang berbeda yaitu di area konservasi TO milik ketua kelompok pembudidaya TO Asyifa'a dan di lahan pekarangan masyarakat. Di area konservasi dihadiri sebanyak 20 orang peserta, sedangkan di lahan pekarangan dihadiri sebanyak 15 orang ibu-ibu rumah tangga.

Pelatihan teknik budidaya di area kebun konservasi dimaksudkan untuk memudahkan peserta dalam melakukan konservasi TO terutama yang tergolong langka karena dapat melihat langsung jenis dan karakteristik morfologi serta teknik pengembangan TO tersebut. Materi pelatihan yang diberikan adalah: teknik persemaian dan pembibitan, teknik budidaya, dan penanganan hasil TO.

Sebelum dilaksanakan pelatihan teknik budidaya di areal konservasi terlebih dahulu diinventarisir jenis yang akan dikonservasi berdasarkan morfologinya, kemudian dilakukan pengisian polibag dan penyiapan benih dan bibit, serta penanaman di polibag seperti yang ditunjukkan pada Gambar 2. 


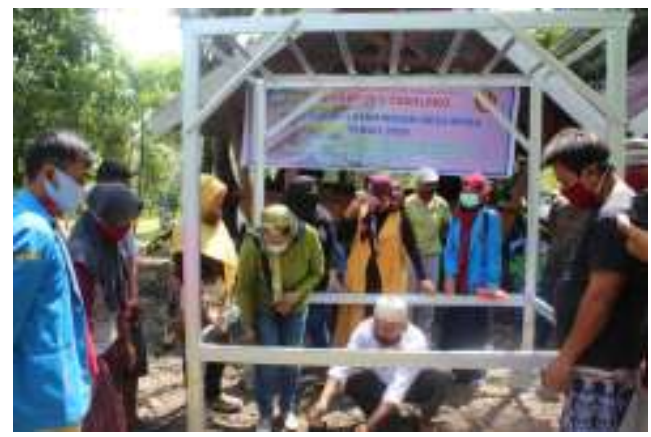

Gambar 2. Dokumentasi penanaman bibit TO di polibag

Pada pelatihan teknik budidaya TO di halaman pekarangan, jenis yang ditanam adalah yang tergolong paling banyak dimanfaatkan oleh masyarakat bila yang menderita sesuatu penyakit serta bernilai ekonomi, seperti tanaman kunyit putih, jahe merah, dan cabe. Jiang (2019) mengemukakan bahwa beberapa jenis tanaman rempah dapat berperan sebagai antioksidan, anti-inflamasi, antitumor dan anti kanker, dapat digunakan sebagai obat. Penanaman dilaksanakan dengan menanam langsung pada lahan pekarangan, dan juga dengan menggunakan polibag. Selain itu masyarakat diajak untuk menata halaman pekarangan agar tetap terlihat rapi dan asri. Sebayang et al. (2020) mengemukakan bahwa budidaya TO seperti jahe yang sesuai dengan Good Agricultural Practices di lahan pekarangan memberikan dampak positif karena mendukung kesehatan masyarakat melalui penyediaan pangan sehat.

Seluruh peserta pelatihan begitu bersemangat mengikuti setiap tahapan penanaman mulai dari persiapan tempat tanam berupa polibag yaitu membuka, membalik dan melipat bagian atasnya, pencampuran media tanam berupa tanah: sekam: pupuk kandang dengan perbandingan 1:1:1. Pengetahuan tentang peranan media tanam untuk pertumbuhan tanaman perlu disampaikan kepada para peserta, karena media tanam merupakan salah satu faktor penting yang menentukan hasil tanaman.

Bibit yang sudah pindah tanam ditempatkan di areal yang ternaungi untuk menghindari penguapan karena tanaman yang baru dipindah masih harus beradaptasi dengan lingkungan. Model pemanfaatan lahan pekarangan untuk budidaya TO seperti ditunjukkan pada Gambar 3 sedangkan tim pelaksana yang mendukung program budidaya TO di lahan pekarangan ditunjukkan pada Gambar 4.

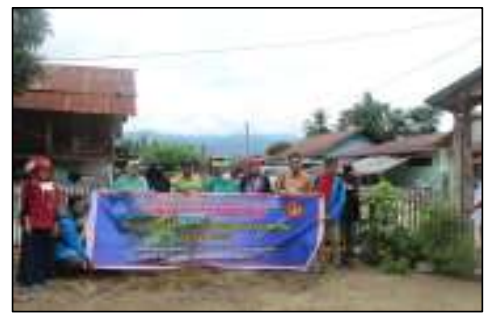

(a)

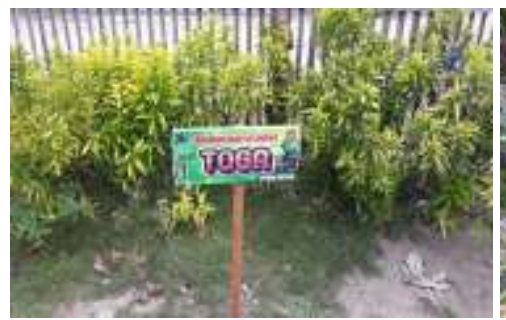

(b)

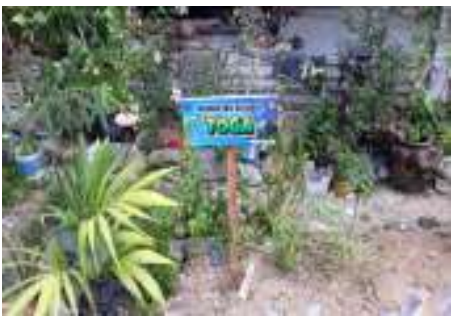

(c)

Gambar 3. (a) Dokumentasi tim pelaksana dan peserta di salah satu halaman pekarangan yang ditanami TOGA, (b) dan (c) Tanaman TOGA di halaman pekarangan

Pemeliharaan tanaman di halaman pekarangan perlu dilakukan agar hasil yang diharapkan dapat diperoleh dengan maksimal. Pemeliharaan yang utama adalah penyiraman dan pembersihan gulma.

Dengan tersedianya TO di halaman pekarangan maka masyarakat dapat menggunakan untuk pengobatan sendiri sebagaimana yang dikemukakan oleh Clayton \& Wolfe (2007) bahwa pelaksanaan swamedikasi (pengobatan diri sendiri) dapat dilakukan jika didukung dengan 
adanya tanaman obat itu sendiri. Lebih lanjut Sari $d k k$. (2019) mengemukakan bahwa penggunaan tanaman obat keluarga (TOGA) bagi masyarakat sebagai salah satu alternatif penanganan masalah kesehatan masyarakat.

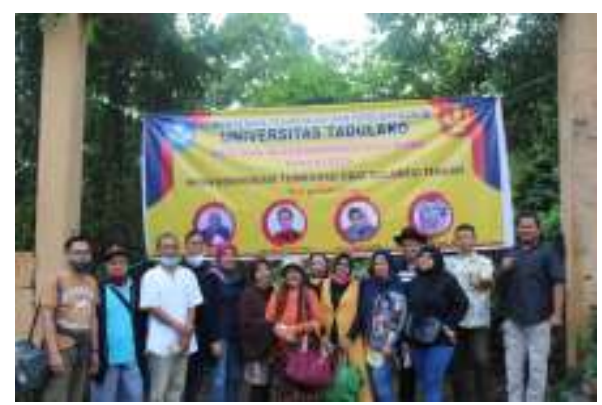

Gambar 4. Dokumentasi tim pelaksana bersama peserta kegiatan di areal konservasi TO

Pembudidayaan TO di halaman pekarangan memberi keuntungan bagi masyarakat antara lain efektif jika dibutuhkan segera, memberikan kesan asri pada halaman rumah karena rata-rata tanaman obat bewarna hijau, serta dapat meningkatkan pendapatan masyarakat. Selain itu juga digunakan sebagai edukasi tanaman herbal atau tanaman obat tradisional kepada anggota keluarga, dikonsumsi sebagai tindakan menjaga kesehatan tubuh dan salah satu tindakan nyata penghijauan tanaman (Dewi \& Widiyawati, 2019).

\section{KESIMPULAN}

Pelaksanaan pelatihan dan demonstrasi teknologi budidaya tumbuhan obat terlaksana dengan baik serta teknologi tersebut diterima oleh masyarakat. Pelaksanaan penyuluhan yang diikuti sebanyak 35 orang peserta dari 2 kelompok mitra kegiatan dapat meningkatkan pengetahuan masyarakat yang ditandai dengan meningkatnya ketrampilan pada saat praktek budidaya tumbuhan obat, baik yang dilaksanakan di areal konservasi maupun di lahan pekarangan. Jumlah peserta yang terlibat secara aktif pada kegiatan demonstrasi teknologi budidaya di 2 tempat yang berbeda sebanyak 35 orang dan 15 orang diantaranya adalah ibu-ibu rumah tangga, menandakan bahwa kegiatan pelatihan pengabdian desa mitra diminati oleh masyarakat. Jenis tumbuhan obat yang dibudidayakan di areal konservasi adalah yang tergolong tumbuhan obat yang tumbuh liar dan langka, sedangkan yang dibudidayakan di lahan pekarangan adalah jenis yang paling banyak dimanfaatkan sebagai obat dan yang bernilai ekonomi

\section{UCAPAN TERIMA KASIH}

Tim pelaksana kegiatan menyampaikan terima kasih kepada Deputi Bidang Penguatan Riset dan Pengembangan, Kementerian Riset dan Teknologi/Badan Riset dan Inovasi Nasional (BRIN) yang telah mendanai pelaksanaan program pemberdayaan desa mitra, sesuai dengan Perjanjian Penugasan Pelaksanaan Program Pengabdian Masyarakat Nomor: 091/SP2H/PPM/DRPM/2020, tanggal 16 Maret 2020

\section{DAFTAR PUSTAKA}

Ashari, Saptana, A., \& Purwantini, T. (2012). Potensi dan prospek pemanfaatan lahan pekarangan untuk mendukung ketahanan pangan. Forum Penelitian Agro Ekonomi, 30(1), 13-30. http://dx.doi.org/10.21082/fae.v30n1.2012.13-30

Clayton, D.H., \& Wolfe, N.D. (1993). The adaptive significance of self-medication, Trends in Ecology \& Evolution, 8(2), 60-63. 
Dalimarta, S. (2000). Atlas tumbuhan obat Indonesia. Jilid 2. Jakarta: Trubus Agriwidya

Departemen Kesehatan RI (1983). Pemanfaatan tanaman obat. Jakarta: Direktorat Jenderal Pengawasan Obat dan Makanan.

Dewi, P.S., Widiyawati, I. (2019). Penerapan teknologi budidaya tanaman obat sebagai upaya pemanfaatan lahan pekarangan di Kelurahan Pabuwaran, Purwokerto, Jawa Tengah. Jurnal Panrita Abdi, 3(2), 105-112. https://doi.org/https://doi.org/10.30653/002.202051.254

Jiang, T.A. (2019). Health benefits of culinary herbs and spices. Journal of AOAC International, 102 (2), 395-414.

Kementerian Kesehatan RI (2011). Pedoman umum budidaya tanaman obat. Jakarta: Badan Penelitian dan Pengembangan Kesehatan. Balai Besar Penelitian dan Pengembangan Tanaman Obat dan Obat Tradisional (B2P2TO0T).

Leakey, R.R.B. \&. Newton, A.C. (1994). Domestication of tropical trees for timber and non-timber products. Paris, France: United Nations Educational, Scientific and Cultural Organization.

Nasriati \& Pujiharti, Y. (2012). Budidaya tanaman obat keluarga (Toga). ) Lampung: Kementerian Pertanian. Badan Penelitian dan Pengembangan Pertanian. Balai Besar Pengkajian dan Pengembangan Teknologi Pertanian. Balai Pengkajian Teknologi Pertanian (BPTP).

Nurmayulis \& Hermita, N. (2015). Potensi tumbuhan obat dalam upaya pemanfaatan lahan pekarangan oleh masyarakat Desa Cimenteng Kawasan Taman Nasional Ujung Kulon. Jurnal Agrologia, 4(1), 1-7.

Parwata, I.M.O.A. (2016). Obat tradisional. Diktat. Denpasar; Jurusan Kimia. Laboratorium Kimia Organik FMIPA Universitas Udayana

Sari, I.D., Yuniar,Y., Siahaan, S., Riswati, \& Syaripuddin, M. (2015). Tradisi masyarakat dalam penanaman dan pemanfaatan tumbuhan obat lekat di pekarangan. Jurnal Kefarmasian Indonesia, 5(2).

Sari, S.M., Ennimay, \& Rasyid, T.A. (2019). Pemanfaatan tanaman obat keluarga (toga) pada masyarakat. Dinamisia 3, Special Issue, 1-7

Sebayang, H. T., Yurlisa, K., Widaryanto, E., \& Aini, N. (2020). Penerapan teknologi budidaya tanaman jahe di pekarangan berbasis pertanian sehat di Desa Bokor Kabupaten Malang.Jurnal Pengabdian Pada Masyarakat, 5(1), 45-50. https://doi.org/https://doi.org/10.30653/002.202051.254

Suriawiria, U. (2000). Obat mujarab dari pekarangan rumah. Jakarta, Penerbit Papas Sinar Sinanti Tampubolon, O.T. (1981). Tumbuhan obat bagi pecinta alam. Jakarta, Bhratara Karya Aksara.

Tudjuka, K., Ningsih, S. \& Toknok, B. (2014). Keanekaragaman jenis tumbuhan obat pada kawasan hutan lindung di Desa Tindoli Kecamatan Pamona Tenggara Kabupaten Poso. Warta Rimba, 2(1), 120-128. 